(C) COBENCE

"Os desafios para formar hoje o engenheiro do amanhã"

\title{
PROJETO DE UMA BANCADA DIDÁTICA PARA ENSINO DE GERAÇÃO DE ENERGIA SOLAR FOTOVOLTAICA
}

Gilberson Landerda Silva Vieira-gilberson_luan@hotmail.com

Universidade Federal do Oeste do Pará, Programa de Ciências e Tecnologia/IEG

Rua Vera Paz, s/n

68040-225 - Santarém - Pará

Nelson de SouzaAmorim-nelson.amorim@ufopa.edu.br

Universidade Federal do Oeste do Pará, Programa de Ciências e Tecnologia/IEG

Rua Vera Paz, $s / n$

68040-225 - Santarém - Pará

Resumo: A formação acadêmica nas universidades brasileiras se baseia basicamente no ensino teórico de diferentes disciplinas, por exemplo: Energia Solar Fotovoltaica. É importante ressaltar que se faz necessário entender certos conceitos complexos acerca deste tipo de energia, logo é fundamental que o estudante entenda de forma prática os principais parâmetros que regem o efeito fotovoltaico. A energia solar é uma fonte de energia proveniente do Sol, sendo esta fundamental para manutenção de toda a vida na Terra, ao mesmo tempo serve de base para todas as outras fontes geradoras de energias existentes. A energia solar fotovoltaica é uma das formas de utilização dessa fonte de energia, considerada limpa e renovável, transforma luz solar em eletricidade através do efeito fotovoltaico. Nesse contexto o presente trabalho apresenta o desenvolvimento e construção de uma bancada didática para o ensino de geração de energia solar fotovoltaica. A bancada didática possui movimentos que simulam os ângulos de declinação solar, o ângulo horário e a variação angular do painel solar. Parâmetros importantes da geração de energia tais como: tensão elétrica, corrente elétrica, irradiação e temperatura, em função do movimento do Sol e movimentos angulares sobre o painel solar foram avaliados.

Palavras-chave: Energia solar. Painel solar. Energia solar fotovoltaica.

\section{INTRODUÇÃO}

A energia solar é uma fonte de energia obtida através do calor e da luz do Sol, esta fonte é altamente disponível e considerada infinita em escala humana, sendo utilizada por diversas tecnologias, por exemplo: energia heliotérmica e arquitetura solar. A energia solar é caracterizada como fonte de energia renovável e sustentável e é utilizada por uma pequena parte da população mundial (PORTAL SOLAR, 2016).

A radiação solar absorvida pela atmosfera está na forma de luz visível e de luz ultravioleta, e é utilizada diretamente pelas plantas para a realização da fotossíntese, onde apenas uma pequena fração da energia solar disponível é utilizada. A energia solar pode ser utilizada de inúmeras formas diferentes, variando também de acordo com o local da superfície da Terra em questão. Desta forma, de acordo com um estudo publicado em 2007 pelo 
Conselho Mundial da Energia, até o ano de 2100, 70\% da energia consumida será de origem solar (TORRES \& SOUSA, 2014, 2015).

É notório que essa fonte de energia é altamente promissora, desta forma o presente trabalho tem como objetivo o desenvolvimento de uma bancada didática para ensino de geração de energia solar fotovoltaica, com uma abordagem didática dos conhecimentos sobre esta energia, ao mesmo tempo, com características de uma mesa didática de estudos contendo movimentos integrados de simulação dos ângulos que definem os Solstícios de Verão e Inverno e Equinócio de Primavera e Outono e os ângulos de forma a simular a radiação solar durante o dia e conseqüentemente a geração de eletricidade sobre o painel solar.

\section{REVISÃO BIBLIOGRÁFICA}

\subsection{Energia Solar}

O Sol é a principal fonte de energia do nosso Sistema Solar, responsável pela manutenção da vida na Terra, essa estrela produz um campo magnético gigantesco ao longo dos planetas, asteróides, estrelas e todos os corpos em movimento pelo Sistema Solar. A Terra possui posição privilegiada no Sistema Solar, com distância aproximada de 150 milhões de quilômetros do Sol, permite que as maiorias das formas de vidas existentes prosperem, utilizando de forma segura a intensidade de luz enviada pelo Sol.

A radiação solar que entra em nossa superfície chega como ondas eletromagnéticas (fótons), de maneira direta ou difusa. Essa radiação solar absorvida pela nossa atmosfera pode está na forma de luz visível e de luz ultravioleta. O espectro da luz solar na superfície da Terra pode ser definido em toda a gama visível, infravermelho e uma pequena gama de radiação ultravioleta (TORRES \& SOUSA, 2014, 2015). Atualmente a energia solar direta se divide emcinco blocos de acordo com o Relatório de fontes renováveis de energia e mitigação damudança climática de 2009 pela IPCC (Intergovernamental Plane on Climate Change), quesão:

- Solar Passiva (Arquitetura Bioclimática);

- Solar Ativa (Aquecimento e Refrigeração Solares);

- Solar Fotovoltaica (Eletricidade);

- Geração de energia com concentradores em altas temperaturas;

- Geração de Hidrogênio.

\subsection{Movimentos e posição da Terra em relação ao Sol}

A Terra possui trajetória elíptica em torno do Sol descrita como translação, essa trajetória possui uma pequena excentricidade $(\varepsilon \approx 0,017)$, a duração dessa trajetória é cerca de 365 dias, com 366 dias a cada quatro anos, essa trajetória determina as estações do ano. O movimento que a Terra executa em seu próprio eixo é descrito como rotação, com aproximadamente 24 horas de duração, esse movimento de rotação determina o dia e a noite.

É verificada a existência de um plano inclinado que a Terra possui em relação ao Sol de aproximadamente $23,45^{\circ}$ com relação à Linha do Equador (CRESESB, 2014). Esse ângulo formado entre o Sol e o plano da Terra em relação à Linha Equatorial é chamado de declinação solar $(\delta)$, com variações angulares entre $-23,45^{\circ}$ ao sul da Linha do Equador e $+23,45^{\circ}$ ao Norte da Linha do Equador. O ângulo de declinação solar permite que a intensidade de luz solar varie em cada hemisfério da Terra no seu movimento de translação em relação ao Sol. 
O ângulo de declinação solar define as estações do ano para cada hemisfério terrestre, para o hemisfério sul quando o ângulo está em $-23,45^{\circ}$, têm-se o solstício de verão que se inicia em 21 de dezembro, quando estiver em $+23,45^{\circ}$ têm-se o solstício de inverno que se inicia em 21 de junho. Quando a declinação solar for $0^{\circ}$, tem-se o equinócio de outono em 21 de março, e, em 21 de setembro o equinócio de primavera. No hemisfério norte ocorre o inverso ao que ocorre no hemisfério sul.

Segundo CRESESB (2014), existem relações geométricas entre os raios solares e a superfície terrestre formadas por alguns ângulos fundamentais para os cálculos de geração de energia solar, os quais são respectivamente:

- Ângulo zenital $\left(\theta_{\mathrm{Z}}\right)$ : que descreve o trajeto do Sol do amanhecer ao pôr-do-sol, e se forma a partir de uma linha vertical local (zênite);

- Ângulo azimutal do Sol $\left(\gamma_{\mathrm{S}}\right)$ : formado pelo plano horizontal com base na direção NorteSul e a projeção dos raios solares.;

- Altura solar $(\alpha)$ : ângulo que se forma entre os raios solares e o plano da superfície terrestre;

- Ângulo azimutal da superfície $(\gamma)$ : formado entre uma linha normal sobre a superfície no plano horizontal, sendo formada também na direção Norte-Sul;

- Inclinação da superfície de captação $(\beta)$ : este ângulo varia de $0^{\circ}$ e $90^{\circ}$, descrito entre a superfície de captação solar e o plano horizontal;

- Ângulo de incidência $(\theta)$ : formado entre a linha normal à superfície coletora e os raios solares incidentes.

A Figura 1 apresenta os movimentos de rotação, translação para o Hemisfério Sul demonstrando suas estações, além de ilustrar o ângulo de declinação solar $(\delta)$ e demais ângulos fundamentais.

Figura 1 - Órbita terrestre inclinada $23,45^{\circ}$ e os ângulos formados entre o Sol em relação ao plano horizontal e a superfície inclinada.
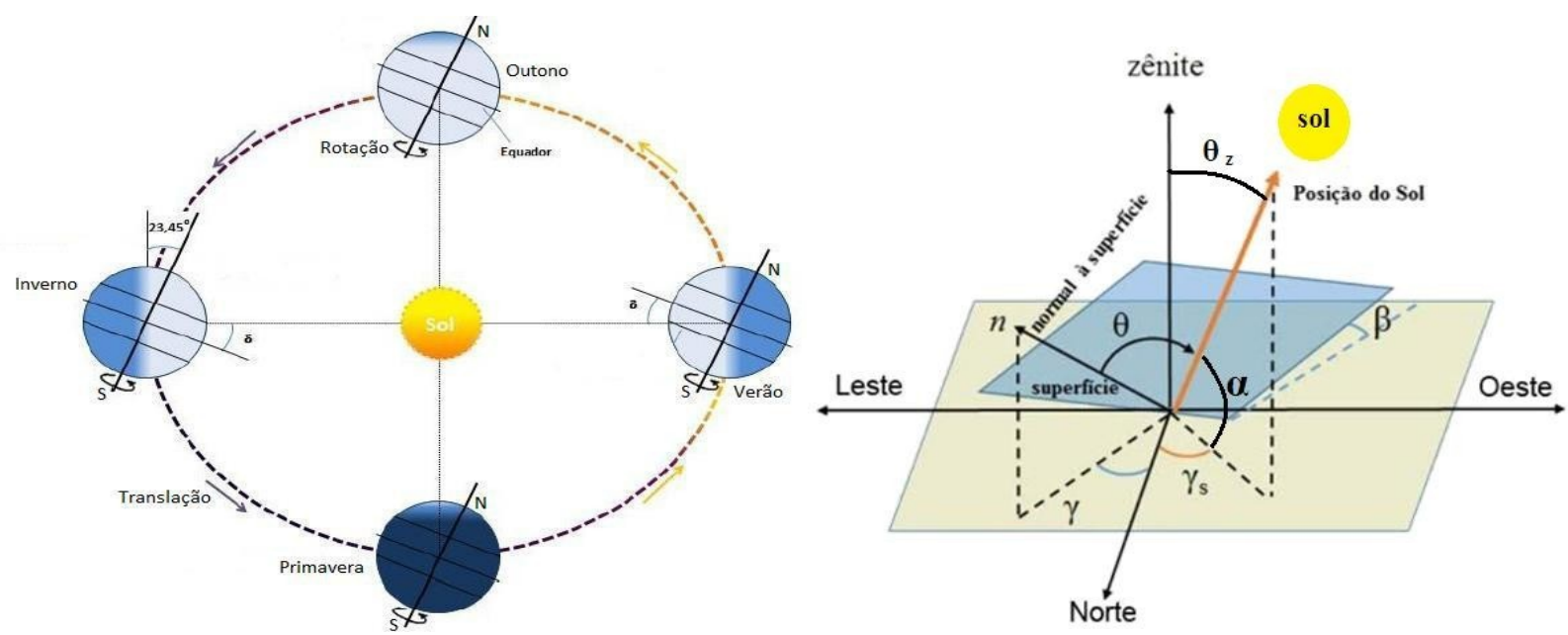

Fonte: CRESESB (2014, figura adaptada).

De acordo com Pinho et. al. (2008), o ângulo formado entre o meridiano do Sol e o plano horizontal local é descrito como ângulo horário $(\omega)$, apresentado na Figura (2), que é o movimento rotacional de eixo da Terra de $360^{\circ}$ em 24 horas, logo, cada hora representa $15^{\circ}$ desse trajeto solar, considerando do amanhecer ao pôr-do-sol $180^{\circ}$, têm-se no amanhecer $90^{\circ}$ positivos, $0^{\circ}$ quando Sol está a pino e $-90^{\circ}$ no pôr-do-sol. 
Figura 2 - Ângulos horários para superfície terrestre no período diurno.

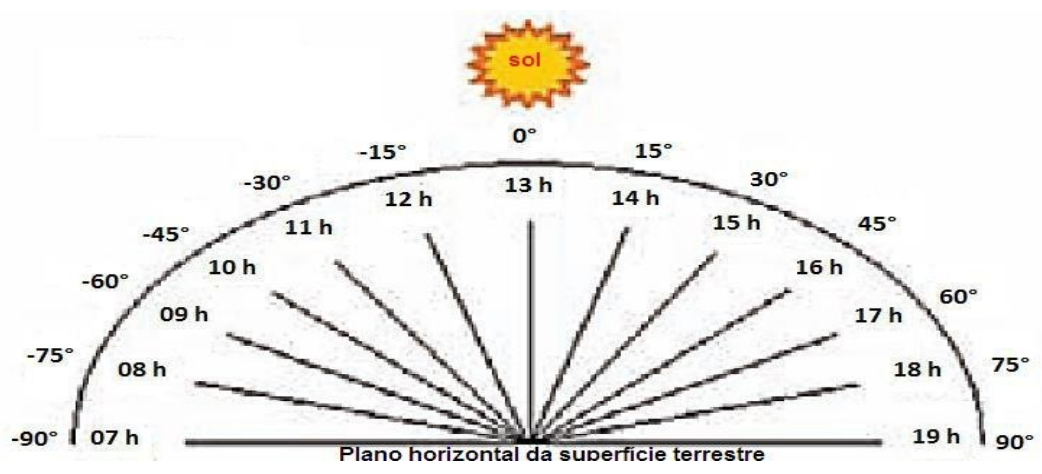

Fonte: PINHO et al. (2008, figura adaptada).

\subsection{Efeito fotovoltaico e fotoelétrico}

O efeito fotovoltaico é a transformação direta da luz solar ou fótons (espectrais de luz) em energia elétrica em uma célula fotovoltaica, em decorrência de fatores físicos e químicos em seu material semicondutor dopado, na incidência de luz os elétrons do semicondutor absorvem os fótons, nessa absorção ocorre o movimento dos elétrons, que ao se deslocarem são puxados por um campo elétrico produzido na junção dopada desse semicondutor. De acordo com Villalva e Gazoli (2012), esse movimento dos elétrons gera uma diferença de potencial ou tensão elétrica na célula fotovoltaica.

De acordo com Villalva e Gazoli (2012), o efeito fotoelétrico consiste na emissão dos elétrons na incidência de luz solar em uma superfície metálica e não metálica através de uma substância, nesse efeito, com a incidência de luz solar os elétrons livres param de se movimentar, ou simplesmente são ejetados, esse efeito não produz diferença de potencial. $\mathrm{Na}$ Figura 3 é apresentado o efeito fotovoltaico e fotoelétrico.

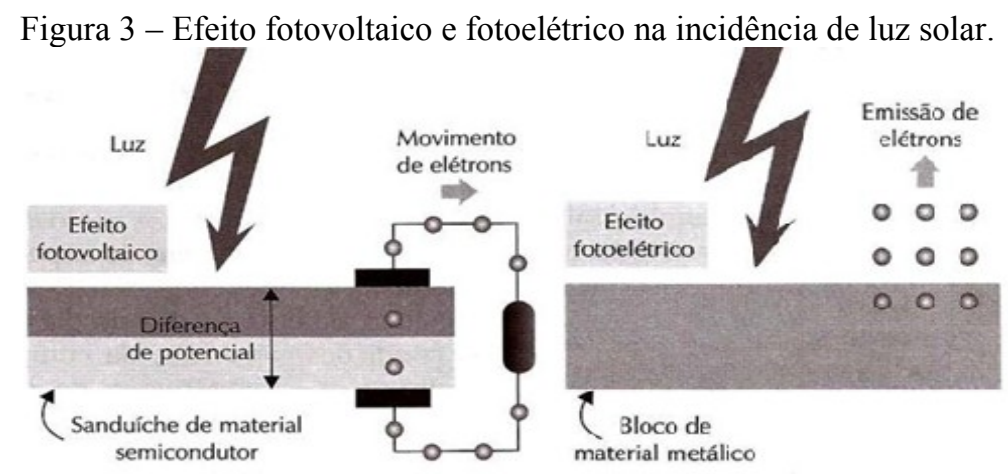

Fonte: VILLALVA e GAZOLI (2012, figura adaptada).

\section{METODOLOGIA}

\subsection{Projeto inicial da bancada didática}

Para o desenvolvimento do projeto inicial utilizou-se o software AutoCAD para obtenção dos desenhos e vistas em 2D, nesta etapa foram definidos os tamanhos e as dimensões da bancada didática baseados no painel solar escolhido, que está em uma posição de eixo terrestre ou seja na Linha Equatorial. Utilizando software Solidworks obteve-se os desenhos em 3D. A Figura 4 apresenta os projetos utilizados para montagem e construção da bancada e a bancada didática em utilização. 


\section{CORENGEF de Educaçâo em Engenharia de Educaçâo em Engenharia da ABENGE}

Figura 4 - Projetos da estrutura da bancada didática, bancada em utilização.
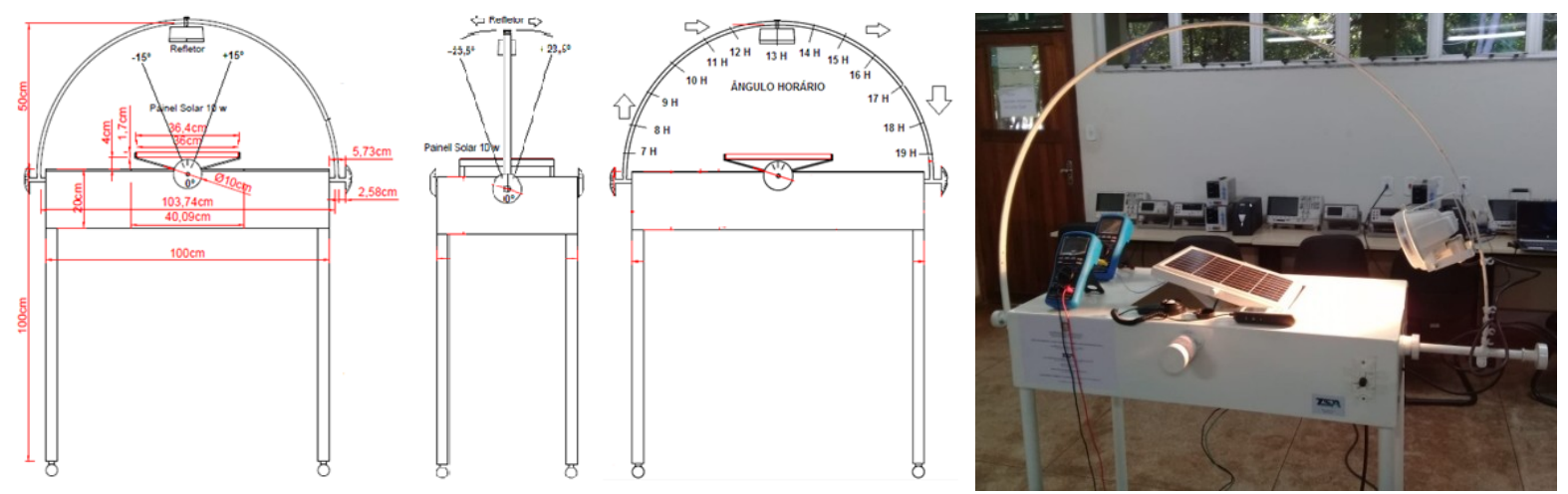

Fonte: Autor (2018).

Os componentes utilizados na bancada didática foram: painel solar fotovoltaico de 10 Watts, dimmer de potencial analógico de $200 \mathrm{~K}$ de resistência, projetor com lâmpada halógena de 500 Watts.

\subsection{Roteiros experimentais propostos}

Roteiro 1: movimento do Sol ao longo do dia para equinócio de outono/primavera para o hemisfério sul, posicionar a declinação ângular em $0^{\circ}$.

Roteiro 2: movimento do Sol ao longo do dia para solstício de verão para o hemisfério sul, posicionar a declinação ângular em $-23,45^{\circ}$.

Roteiro 3: movimento do Sol ao longo do dia para solstício de inverno para o hemisfério sul, posicionar a declinação ângular em $+23,45^{\circ}$.

\section{Procedimentos para todos os roteiros:}

$>$ Posicionar o painel solar sobre o seu encaixe localizado no eixo superior da bancada;

$>$ Colocar o ajuste do ângulo de declinação solar em ângulo $\left(0^{\circ},-23,45^{\circ}\right.$ ou $\left.+23,45^{\circ}\right)$;

$>$ Definir o posicionamento do projetor em cada posição horária, entre 7 horas e 19 horas;

$>$ Colocar os ajustes do painel solar definidos: $15^{\circ} \mathrm{O}, 0^{\circ}$ e $15^{\circ} \mathrm{L}$;

$>$ Ligar a fonte de iluminação e ajustar intensidade de luz do dimmer no giro máximo;

$>$ Utilizar medidores de tensão e corrente, termopar para aferição de temperatura e piroeliômetro digital para medidas de irradiância;

$>$ Os dados experimentais coletados para cada roteiro devem ser dispostos em uma tabela.

\section{RESULTADOS E DISCUSSÕES}

\section{Roteiro 1}

Os resultados obtidos para o roteiro são apresentados na Tabela 1 . 
Tabela 1- Dados experimentais para o roteiro 1.

\begin{tabular}{|c|c|c|c|c|c|c|c|c|c|c|c|c|}
\hline \multicolumn{13}{|c|}{ Estrutura com declinação solar $(\delta)$ em $0^{\circ}$ para estaç̃es de outono e primavera. } \\
\hline \multirow{2}{*}{ Hora } & \multicolumn{4}{|c|}{ Placa em $15^{\circ}$ Oeste } & \multicolumn{4}{|c|}{ Placa em $0^{\circ}$} & \multicolumn{4}{|c|}{ Placa em $15^{\circ}$ Leste } \\
\hline & $\mathrm{V}$ & $\mathrm{A}$ & ${ }^{\circ} \mathrm{C}$ & $\mathrm{W} / \mathrm{m}^{2}$ & $\mathrm{~V}$ & A & ${ }^{\circ} \mathrm{C}$ & $\mathrm{W} / \mathrm{m}^{2}$ & $\mathrm{~V}$ & $\mathrm{~A}$ & ${ }^{\circ} \mathrm{C}$ & $\mathrm{W} / \mathrm{m}^{2}$ \\
\hline $07 \mathrm{~h}$ & 12,63 & 0,0018 & 26,50 & 7 & 12,32 & 0,0019 & 26,90 & 9 & 17,87 & 0,0145 & 28,70 & 102 \\
\hline $08 \mathrm{~h}$ & 12,38 & 0,0021 & 28,30 & 9 & 17,40 & 0,0121 & 29,10 & 102 & 19,94 & 0,0362 & 28,70 & 226 \\
\hline $09 \mathrm{~h}$ & 16,13 & 0,0085 & 33,30 & 55 & 18,60 & 0,0296 & 34,10 & 168 & 19,77 & 0,0529 & 33,90 & 298 \\
\hline $10 \mathrm{~h}$ & 18,82 & 0,0294 & 32,70 & 171 & 19,75 & 0,0560 & 33,80 & 295 & 20,14 & 0,0838 & 34,20 & 456 \\
\hline $11 \mathrm{~h}$ & 19,50 & 0,0553 & 33,20 & 326 & 19,99 & 0,0843 & 34,80 & 521 & 20,00 & 0,1163 & 34,50 & 670 \\
\hline $12 \mathrm{~h}$ & 19,58 & 0,0707 & 34,30 & 323 & 19,97 & 0,0976 & 35,80 & 505 & 20,15 & 0,1276 & 34,20 & 603 \\
\hline $13 \mathrm{~h}$ & 19,80 & 0,0830 & 34,40 & 463 & 19,97 & 0,1098 & 34,40 & 569 & 20,11 & 0,1282 & 35,60 & 565 \\
\hline $14 \mathrm{~h}$ & 20,04 & 0,1056 & 33,80 & 555 & 20,07 & 0,1289 & 35,70 & 573 & 20,00 & 0,0960 & 33,70 & 474 \\
\hline $15 \mathrm{~h}$ & 20,13 & 0,1299 & 33,70 & 562 & 20,00 & 0,0983 & 34,10 & 514 & 19,61 & 0,0633 & 33,60 & 349 \\
\hline $16 \mathrm{~h}$ & 20,21 & 0,1063 & 33,50 & 538 & 20,03 & 0,0719 & 33,40 & 399 & 19,28 & 0,0405 & 32,80 & 245 \\
\hline $17 \mathrm{~h}$ & 20,21 & 0,0793 & 33,40 & 419 & 19,59 & 0,0443 & 32,10 & 265 & 17,81 & 0,0168 & 32,60 & 103 \\
\hline $18 \mathrm{~h}$ & 19,89 & 0,0510 & 32,00 & 325 & 18,38 & 0,0202 & 32,10 & 132 & 11,95 & 0,0022 & 31,30 & 17 \\
\hline $19 \mathrm{~h}$ & 18,87 & 0,0232 & 31,30 & 179 & 12,88 & 0,0028 & 31,10 & 20 & 12,17 & 0,0020 & 30,70 & 5 \\
\hline
\end{tabular}

Fonte: Autor (2018).

Para a Tabela 1 e Gráfico 1, foi observado que o comportamento dos parâmetros para o painel em $15^{\circ} \mathrm{O}$, apresentou baixos índices de geração de tensão e corrente nas primeiras horas do dia e altos índices nas horas finais do dia, e o oposto para a placa a $15^{\circ} \mathrm{L}$. Para o painel em $0^{\circ}$, foi observado valores médios de tensão e corrente nas primeiras e ultimas horas do dia, para o meio do dia o painel apresentou altos valores de tensão e corrente. Esse comportamento ocorre devido os parâmetros de irradiação e temperatura influenciarem diretamente nos valores de tensão e corrente, ou seja, quanto maior a irradiação, maior será a tensão gerada e corrente.

Gráfico 1 - Parâmetros do Roteiro 1: tensão, corrente, temperatura e irradiância.

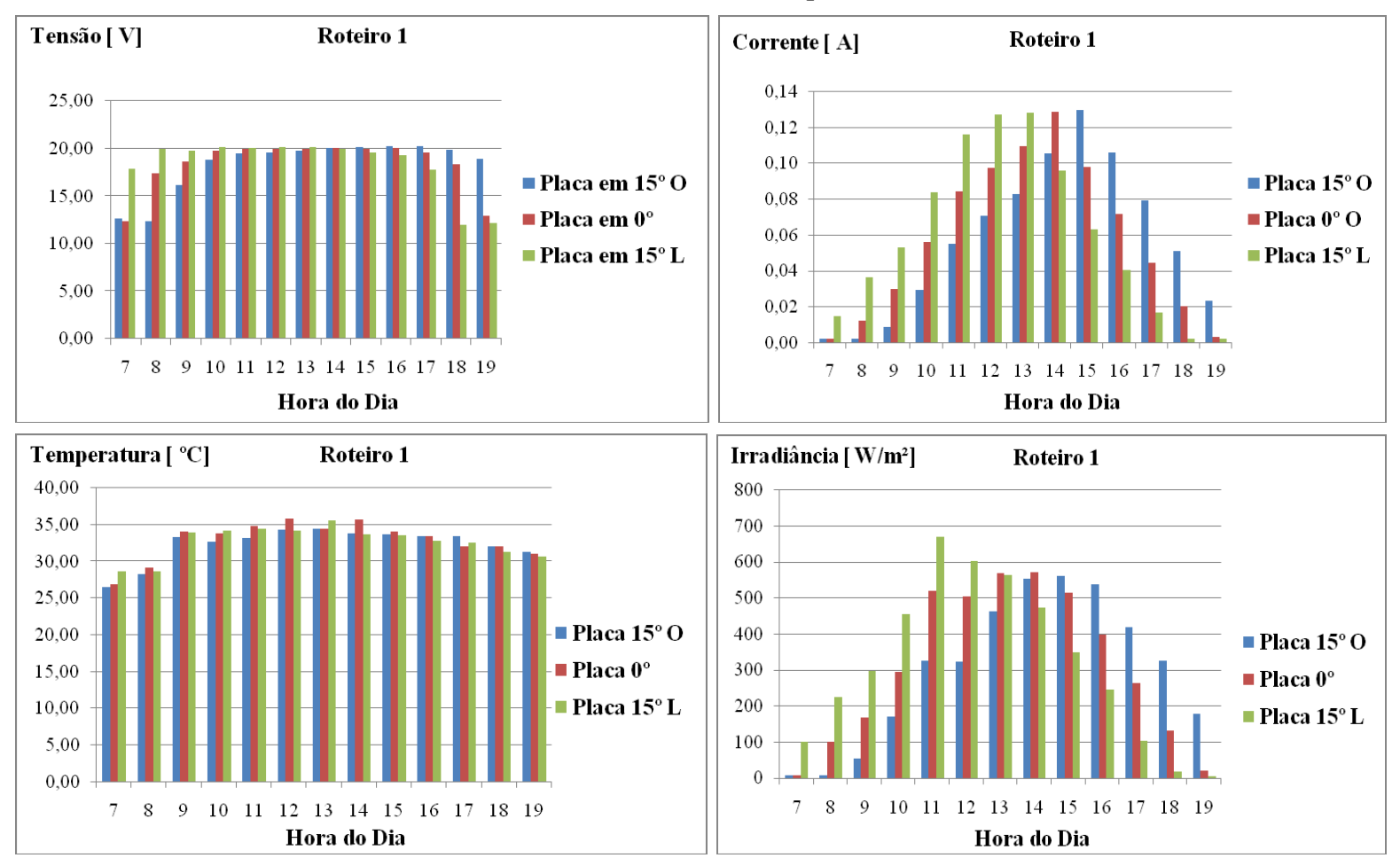

Fonte: Autor (2018). 
(C) COBENCEE =

"Os desafios para formar hoje o engenheiro do amanhã"

\section{Roteiro 2}

Os resultados obtidos para roteiro são apresentados na Tabela 2.

Tabela 2- Dados experimentais para o roteiro 2.

\begin{tabular}{|c|c|c|c|c|c|c|c|c|c|c|c|c|}
\hline \multicolumn{13}{|c|}{ Estrutura com declinacão solar $(\delta)$ em $-23.45^{\circ}$ para estacão verão. } \\
\hline \multirow{2}{*}{ Hora } & \multicolumn{4}{|c|}{ Placa em $15^{\circ}$ Oeste } & \multicolumn{4}{|c|}{ Placa em $0^{\circ}$} & \multicolumn{4}{|c|}{ Placa em $15^{\circ}$ Leste } \\
\hline & $\mathrm{V}$ & A & ${ }^{\circ} \mathrm{C}$ & $\mathrm{W} / \mathrm{m}$ & $\mathrm{V}$ & A & ${ }^{\circ} \mathrm{C}$ & $\mathrm{W} / \mathrm{m}^{2}$ & $\mathrm{~V}$ & A & ${ }^{\circ} \mathrm{C}$ & $\mathrm{W} / \mathrm{m}^{2}$ \\
\hline $07 \mathrm{~h}$ & 12,17 & 0,0019 & 26,90 & 7 & 12,22 & 0,0018 & 26,90 & 8 & 17,75 & 0,011 & 28,60 & 90 \\
\hline $08 \mathrm{~h}$ & 12,37 & 0,0020 & 27,40 & 9 & 17,08 & 0,0106 & 27,70 & 69 & 19,30 & 0,032 & 28,60 & 201 \\
\hline $09 \mathrm{~h}$ & 15,55 & 0,0057 & 33,20 & 36 & 18,60 & 0,0225 & 33,00 & 123 & 19,54 & 0,041 & 32,10 & 236 \\
\hline $10 \mathrm{~h}$ & 18,30 & 0,0220 & 33,30 & 120 & 19,49 & 0,0429 & 33,00 & 237 & 19,96 & 0,0 & 32,30 & 335 \\
\hline $11 \mathrm{~h}$ & 19,35 & 0,0411 & 33,30 & 206 & 19,86 & 0,0624 & 33,80 & 308 & 20,04 & 0,083 & 33,20 & 364 \\
\hline $12 \mathrm{~h}$ & 19,58 & 0,0528 & 30,20 & 249 & 19,98 & 0,0704 & 30,00 & 324 & 20,16 & 0,088 & 34,90 & 356 \\
\hline $13 \mathrm{~h}$ & 19,67 & 0,0627 & 32,40 & 287 & 19,78 & 0,0793 & 35,30 & 340 & 19,84 & 0,083 & 34,80 & 326 \\
\hline $14 \mathrm{~h}$ & 19,77 & 0,0785 & 36,30 & 357 & 19,71 & 0,0866 & 36,00 & 357 & 19,55 & 0,075 & 35,00 & 303 \\
\hline $15 \mathrm{~h}$ & 20,00 & 0,0901 & 36,30 & 345 & 19,80 & 0,0772 & 36,00 & 306 & 19,32 & 0,050 & 33,40 & 214 \\
\hline $16 \mathrm{~h}$ & 20,04 & 0,0826 & 29,00 & 315 & & 0,0561 & 29,60 & 241 & 18,72 & 0,030 & 31,60 & 145 \\
\hline $17 \mathrm{~h}$ & 19,94 & 0,0624 & 32,00 & 257 & 19, & 0,0342 & 33,00 & 160 & 16,50 & 0,009 & 30,10 & 58 \\
\hline $18 \mathrm{~h}$ & 19,67 & 0,0435 & 28,00 & 240 & 17,75 & 0,0150 & 28,00 & 96 & 12,07 & 0,001 & 28,00 & 11 \\
\hline $19 \mathrm{~h}$ & 18,58 & 0,0198 & 27,00 & 146 & 12,39 & 0,0018 & 27,00 & 17 & 12,07 & 0,001 & 27,00 & 5 \\
\hline
\end{tabular}

Fonte: Autor (2018).

Para a Tabela 2 e Gráfico 2 o comportamento dos parâmetros para o painel em $15^{\circ} \mathrm{O}$, apresentou baixos índices de geração de tensão e corrente nas primeiras horas do dia e altos índices nas horas finais do dia, e o oposto para a placa a $15^{\circ} \mathrm{L}$. Para o painel em $0^{\circ}$, foi observado valores médios de tensão e corrente nas primeiras e ultimas horas do dia, para o meio do dia o painel apresentou altos valores de tensão e corrente. Esse comportamento ocorre devido aos parâmetros de irradiação e temperatura influenciarem diretamente nos valores de tensão e corrente, ou seja, quanto maior a irradiação, maior será a tensão gerada e corrente.

Gráfico 2 - Parâmetros do Roteiro 2: tensão, corrente, temperatura e irradiância.

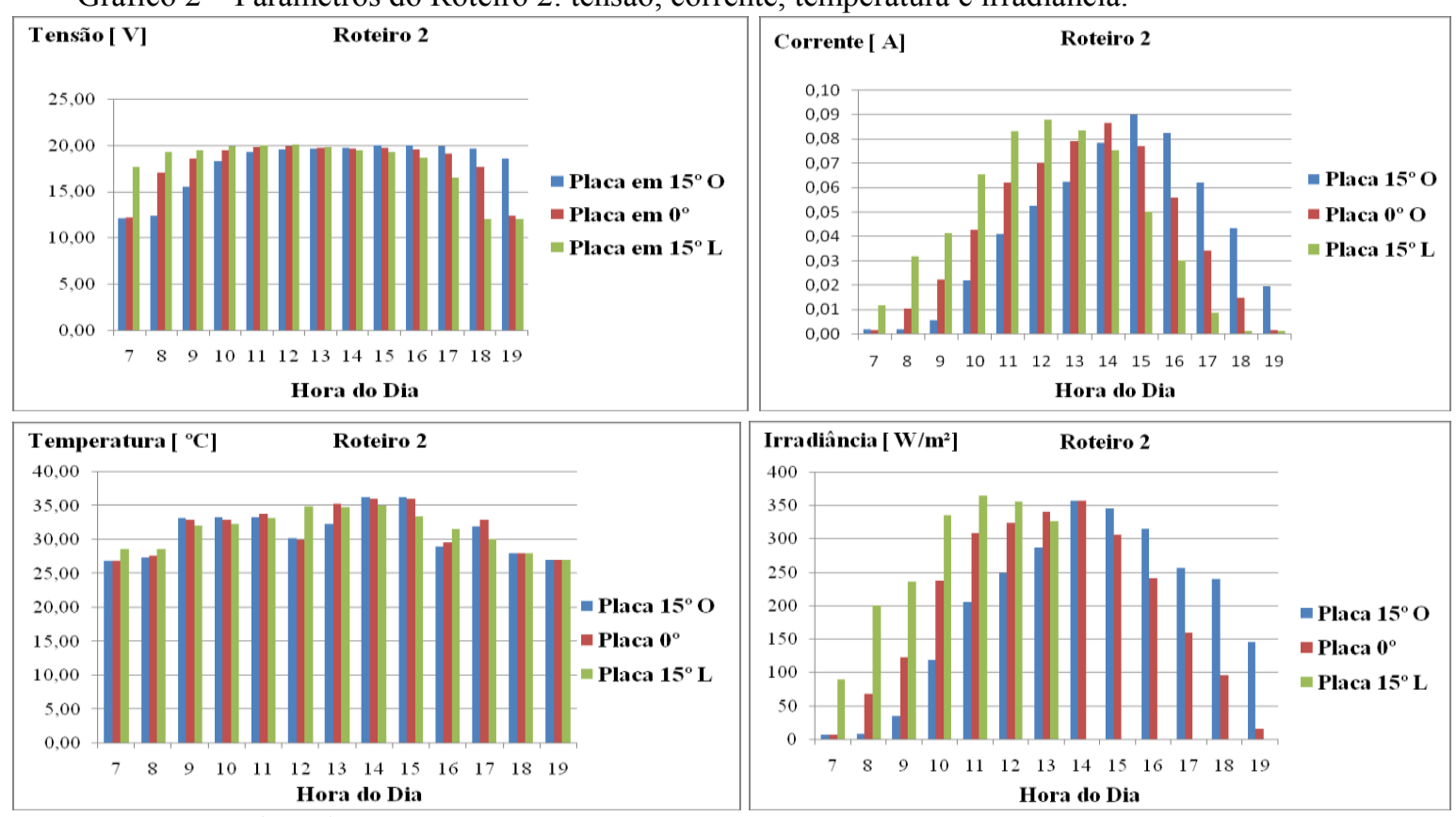

Fonte: Autor (2018). 
(C) COBENCEE =

"Os desafios para formar hoje o engenheiro do amanhã"

\section{Roteiro 3}

Os resultados obtidos para o roteiro são apresentados na Tabela 3.

Tabela 3- Dados experimentais para o roteiro 3.

\begin{tabular}{|c|c|c|c|c|c|c|c|c|c|c|c|c|}
\hline \multicolumn{13}{|c|}{ Estrutura com declinacão solar $(\delta)$ em $+23,45^{\circ}$ para estacão inverno. } \\
\hline \multirow{2}{*}{ Hora } & \multicolumn{4}{|c|}{ Placa em $15^{\circ}$ Oeste } & \multicolumn{4}{|c|}{ Placa em $0^{\circ}$} & \multicolumn{4}{|c|}{ Placa em $15^{\circ}$ Leste } \\
\hline & $\mathrm{V}$ & $\mathrm{A}$ & ${ }^{\circ} \mathrm{C}$ & $\mathrm{W} / \mathrm{m}^{2}$ & $\mathrm{~V}$ & A & ${ }^{\circ} \mathrm{C}$ & $\mathrm{W} / \mathrm{m}^{2}$ & $\mathrm{~V}$ & $\Lambda$ & ${ }^{\circ} \mathrm{C}$ & $\mathrm{W} / \mathrm{m}^{2}$ \\
\hline $07 \mathrm{~h}$ & 11,76 & 0016 & & 7 & 11,25 & 0,0014 & 28,50 & 8 & & 0,0105 & 28,70 & 69 \\
\hline $08 \mathrm{~h}$ & 11,58 & 0,0017 & 30,00 & & 6,21 & 0,0084 & 30,50 & 61 & & & 29,50 & 185 \\
\hline $09 \mathrm{~h}$ & 15,0 & & 34,2 & 46 & & & 31,5 & & & & 29,90 & 293 \\
\hline $10 \mathrm{~h}$ & $17 \mathrm{n}^{\circ}$ & 0,0215 & 31, & 14 & & & & & & & 30,40 & 462 \\
\hline $11 \mathrm{~h}$ & & & & & & & & & & & 30,50 & 557 \\
\hline $12 \mathrm{~h}$ & 19,13 & 0,0582 & 33,60 & 393 & 19,34 & 0,0787 & 33,00 & 55 & & & 30,90 & 573 \\
\hline $13 \mathrm{~h}$ & 19 , & & & & & & & & & & 31,30 & 518 \\
\hline $14 \mathrm{~h}$ & 19,61 & 0,0865 & 32,8 & 588 & 9,54 & 0,0974 & 33,10 & 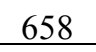 & 19 & 26 & 31,40 & 468 \\
\hline $15 \mathrm{~h}$ & & & & & & & & & & & 31,00 & 349 \\
\hline $16 \mathrm{~h}$ & 19,6 & & & 57 & & & & 39 & & & 30,30 & 213 \\
\hline $17 \mathrm{~h}$ & 19,2 & & & 45 & & & 29,60 & 266 & & & 30,60 & 93 \\
\hline $18 \mathrm{~h}$ & 19,09 & 0,0382 & 30,10 & 31 & & & & 11 & & & 29,40 & 13 \\
\hline $19 \mathrm{~h}$ & 17,70 & 0,0161 & 30,30 & 141 & 12,25 & 0,0016 & 29,30 & 14 & 11,980 & 0,0014 & 29,20 & 8 \\
\hline
\end{tabular}

Fonte: Autor (2018).

Para a Tabela 3 e Gráfico 3 o comportamento dos parâmetros para o painel em $15^{\circ} \mathrm{O}$, apresentou baixos índices de geração de tensão e corrente nas primeiras horas do dia e altos índices nas horas finais do dia, e o oposto para o painel a $15^{\circ} \mathrm{L}$. Para o painel em $0^{\circ}$, foi observado valores médios de tensão e corrente nas primeiras e ultimas horas do dia, para o meio do dia o painel apresentou altos valores de tensão e corrente. De forma semelhante aos Roteiros 1 e 2, esse comportamento ocorreu devido aos parâmetros de irradiação e temperatura influenciarem diretamente nos valores de tensão e corrente, ou seja, quanto maior a irradiação, maior será a tensão gerada e corrente.

Gráfico 3 - Parâmetros do Roteiro 3: tensão, corrente, temperatura e irradiância.

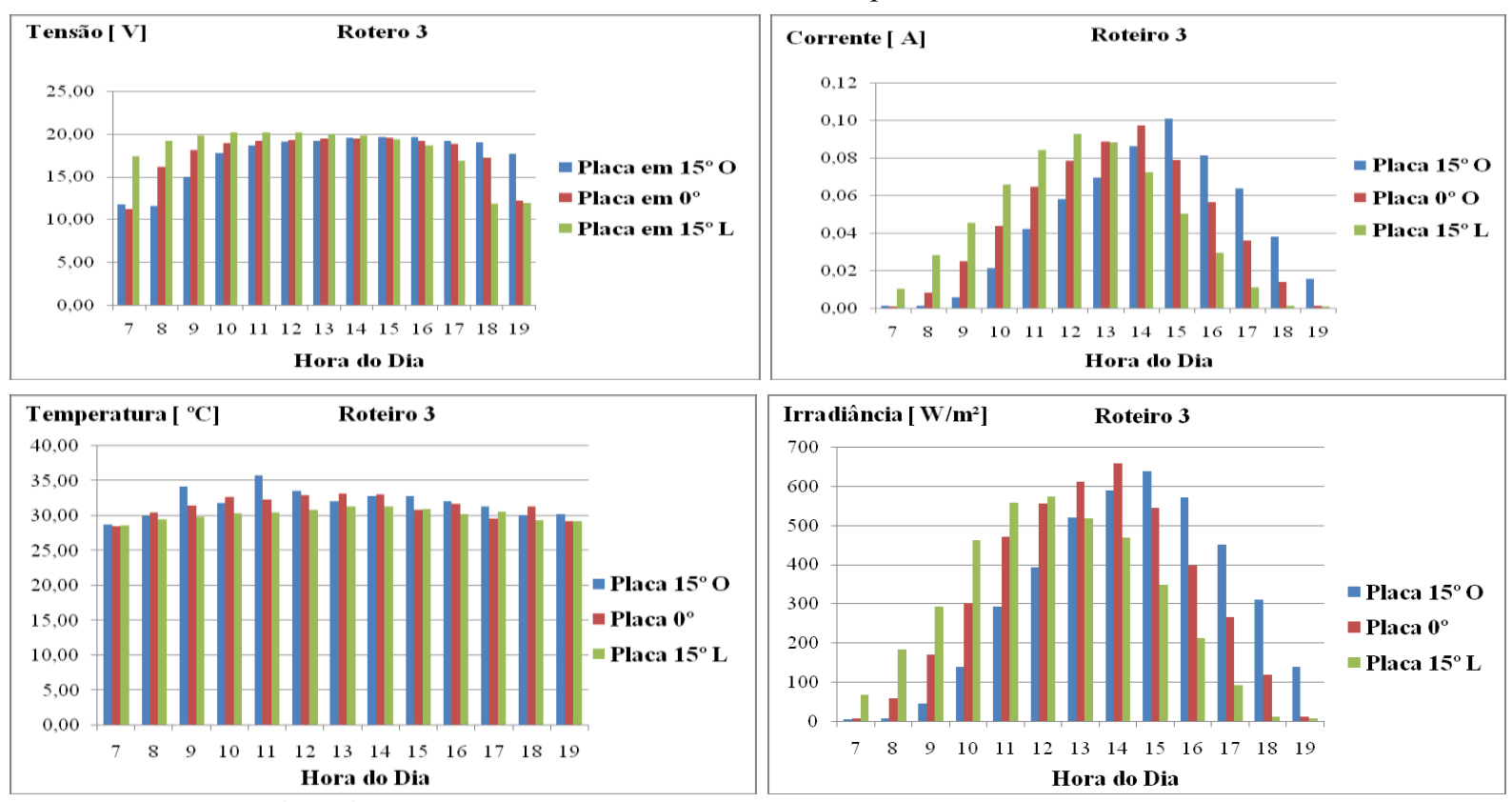

Fonte: Autor (2018). 
(C) COBENCEE =

"Os desafios para formar hoje o engenheiro do amanhã"

\section{CONSIDERAÇÕES FINAIS}

O presente estudo permitiu concluir que a partir dos dados experimentais obtidos, estes se mostraram satisfatórios, ressaltando a idéia de que a geração de energia elétrica através do efeito fotovoltaico sobre o painel solar é influenciada pela sua inclinação e direção de instalação, bem como pela variação da intensidade de luz, pelo posicionamento solar observado através da declinação angular e pelo ângulo horário, onde a posição solar nas diferentes horas do dia influencia diretamente nas variações da geração de energia elétrica. Portanto, a bancada didática desenvolvida pode contribuir de forma satisfatória no aprendizado dos discentes em disciplinas que envolvam o conceito de Energia Solar.

\section{Agradecimentos}

Os autores agradecem à Pró-reitoria de Pesquisa, Pós-Graduação e Inovação Tecnológica da Universidade Federal do Oeste do Pará e a empresa TSA Indústria pela parceria na construção da bancada didática.

\section{REFERÊNCIAS}

ALVES, Alceu Ferreira. Energia solar fotovoltaica. Disponível em: http//:www.feb.unesp.br/dee/docentes/alceu. Acesso em 21 set. 2016.

AGÊNCIA NACIONAL DE ENERGIA ELÉTRICA. Resolução Normativa no 482, de 17 abril de 2012.

AUTOCAD 2017, Autodesk: Disponível em: http://www.autodesk.com.br. Acesso em: 25 nov. 2016.

CENTRO DE REFERÊNCIA PARA ENERGIA SOLAR E EÓLICA SÉRGIO DE SALVO BRITO (CRESESB). Manual de engenharia para sistemas fotovoltaicos - Rio de Janeiro: Centro de Pesquisas em Energia Elétrica - CEPEL; março de 2014.

INTERNATIONAL ENERGY AGENCY (IEA). Snapshot of global photovoltaic markets. Mary Brunisholz, IEA PVPS, 2016.

PINHO, João Tavares et al. Sistemas híbridos: Soluções energéticas para a Amazônia, 2008.

PORTAL SOLAR. Energia solar fotovoltaica. Disponível em:

http://www.portalsolar.com.br. Acesso em: 15 nov. 2016.

RODRIGUES, Pedro Rabelo. Projeto de bancada didática experimental para o uso de energia solar e eólica. 2014. 96 f. Monografia (Graduação) - Faculdade UnB Gama - FGA, Universidade de Brasília, Brasília, 2014.

RODRIGUES, Seire Cristina Pereira. Projeto de uma bancada didática para testes em painéis fotovoltaicos. 2014. 50 f. Monografia (Graduação) - Faculdade UnB Gama - FGA, Universidade de Brasília, Brasília, 2014.

SOLIDWORKS. Disponível em: http://www.solidworks.com. Acesso em: 25 jan. 2017.

TORRES, Manuel Firmino da Silva; SOUSA, Armando Jorge Miranda de. PROJETO FEUP. Energia solar: Faculdade de Engenharia; Universidade do Porto; Porto-Portugal, 2014/2015. 
VIEIRA, Gilberson Lander da Silva. Projeto de uma bancada didática para ensino de geração de energia solar fotovoltaica. 2018. 65 f. Monografia (Graduação) - Instituto de Engenharia e Geociências - Programa de Ciências e Tecnologia, Universidade Federal do Oeste do Pará, Santarém, 2018.

VILLALVA, Marcelo Gradella; GAZOLI, Jonas Rafael. Energia solar fotovoltaica: Conceitos e Aplicações; Sistemas isolados e conectados à rede. Editora Érica, 2012.

\title{
DESIGN OF EQUIPMENT DIDACTIC FOR PHOTOVOLTAIC SOLAR ENERGY GENERATION.
}

\begin{abstract}
The academic qualification at Brazilian universities is majority based in theoretical teaching of different disciplines, for example: Photovoltaic Solar Energy. It is important to emphasize that is necessary to understand fundamentals concepts about the type of energy, so it is essential that the student understand in a practical manner the main parameters that govern the photovoltaic effect. Solar energy is a source of energy from the Sun, which is fundamental for the maintenance of life on Earth, at the same time it serves as a basis for all other existing sources of energy generation. Photovoltaic solar energy is one of the manner of using this energy source, considered clean and renewable, it transforms sunlight into electricity through the photovoltaic effect. In this context, the present work aims the development and construction of a didactic equipment for teaching photovoltaic solar energy generation. The didactic equipment simulate the angles of solar inclination, hour angle and the variation angle of the solar panel. Important parameters of energy generation such as: electric voltage, electric current, irradiation and temperature, as a function of the movement of the Sun in relation to the angular movements on the solar panel were evaluated.
\end{abstract}

Keywords: Solar energy. Solar panel. Photovoltaic solar energy. 